\title{
Alcohol and tobacco use in Portuguese adolescents: The relationship with social factors, future expectations, physical and psychological symptoms
}

\section{Ana Cerqueira $^{1,2,3}$ (1) | Tania Gaspar ${ }^{1,3}$ ｜ Fábio Botelho Guedes ${ }^{1,2,3}$ Emmanuelle Godeau ${ }^{4,5}$ Margarida Gaspar de Matos ${ }^{1,6}$}

${ }^{1}$ Institute of Environmental Health (ISAMB)/Aventura Social/Faculty of Medicine, University of Lisbon (FMUL), Lisbon, Portugal

${ }^{2}$ Faculty of Human Kinetics, University of Lisbon/FMH-UL, Lisbon, Portugal

${ }^{3}$ Lusíada Center for Research in Social Work and Social Intervention (CLISSIS), Lusíada University of Lisbon, Lisbon, Portugal

${ }^{4}$ French School of Public Health, EHESP, Rennes, France

${ }^{5}$ CERPOP, UMR 1295, unité mixte UMR INSERM, Université Toulouse III Paul Sabatier, Team SPHERE, Toulouse, France

${ }^{6}$ APPSYci, ISPA, University Institute, Lisbon, Portugal

\section{Correspondence}

Ana Cerqueira, Institute of Environmental Health (ISAMB)/ Aventura Social/Faculty of Medicine, University of Lisbon (FMUL), Lisbon, Portugal.

Email: cerqueira.apm@gmail.com

\begin{abstract}
The influence that social factors (relationship with teachers, peers and family support), future expectations, physical and psychological symptoms exert on the adolescents' tobacco and alcohol consumption is analyzed, and the differences between users and non-users are analyzed as well. This work is part of the HBSC study. The results show that substance use is associated with more physical and psychological symptoms, worse relationship with teachers and peers, less family support, and lower future expectations. It is important to intervene towards the construction of more positive future expectations and relationships and the promotion of physical and psychological well-being, as protective factors against substance use.
\end{abstract}

\section{K E Y W O R D S}

adolescence, alcohol, family, future expectations, mental health, peers, school, tobacco 


\section{INTRODUCTION}

It is during adolescence that young people acquire new learnings, knowledge and skills that will allow them to have an adjusted and successful transition into adulthood and prepare them for the new challenges associated with it. Adolescents are inserted in a certain cultural, social and family context while they develop their own identity (Dahl et al., 2018).

There is evidence that this stage of development is more prone to the involvement in risk behaviours, such as alcohol and tobacco consumption (Balaguer et al., 2017; Duell \& Steinberg, 2019; Knoll et al., 2015). In addition, the search for new experiences also tends to increase during this developmental stage, which can be associated with increased involvement in risk behaviors (Duell \& Steinberg, 2019; Patrick \& Schulenberg, 2014; Sznitman \& Engel-Yeger, 2017).

The development of this type of risk behaviours has negative repercussions on the adolescents' health (Janáček et al., 2021; Lewis \& Russel, 2014; MacArthur et al., 2016; Patterson et al., 2020), which appears to be associated with an increase in morbidity and mortality and constitutes a considerable challenge for the public health. Substance use (i.e., alcohol, tobacco and drugs) has physical, mental and social consequences. It has a considerable impact on the individual, the family and the community in general (Das et al., 2016; Sudhinaraset et al., 2016), and it contributes to a low school performance, injuries and violence, and sexual risk behaviours, among other adverse aspects (Sznitman \& Engel-Yeger, 2017).

Alcohol and tobacco consumption during adolescence is a very relevant concern with regard to public health, and it remains a serious challenge even if it has been addressed by public policies and in general tends to decrease at least at a European level (Ansari-Moghaddam et al., 2016; ESPAD Group, 2020; Inchley et al., 2020).

It is essential for adolescents to develop the ability to adapt to all the changes and challenges that are common in this phase of development and to learn strategies to deal with adversity. During adolescence, there is a greater susceptibility to experimentation with alcohol and tobacco and coping mechanisms can influence the involvement in this type of behaviour. Evidence in the literature points to coping strategies as a protective factor against substance use (Gallupe, 2014; McConnell et al., 2014).

There are several risk factors with regard to substance use by adolescents, namely, (a) sociodemographic variables (e.g., gender, age, socioeconomic status), (b) family variables, (c) variables associated with the peer group, (d) personal characteristics and (e) behavioural variables (Guillén et al., 2015). Regarding the family context, the existence of a good relationship between members, cohesion, and proximity are protective factors regarding adversity (Fosco et al., 2012; Gordon et al., 2020; Guillén et al., 2015; van Ryzin et al., 2012). Parental monitoring and support appear to be a protective factor for alcohol and tobacco consumption in adolescents (Bahr \& Hoffman, 2010; Chaplin et al., 2012; Gutman et al., 2011; Ryan et al., 2010; Sudhinaraset et al., 2016), even when the peer group is composed of users (Bahr \& Hoffman, 2010). There is evidence that negative relationships with parents and peers tend to result in feelings of loneliness and unhappiness, which is reflected in a decrease in the adolescents' psychological well-being (Cerqueira et al., 2019; Tomé et al., 2015).

The relationship with the peer group is an aspect that gains special relevance during adolescence, and young people tend to spend more time with their peers than with their families (van Hoorn et al., 2016; Knoll et al., 2015). The influence that the peer group has on the adolescents can be positive or negative and can cause both protective and health risk behaviours (van Hoorn et al., 2016; Wang et al., 2017). 
According to the theory of social learning (Bandura, 1986), the adolescents acquire social behaviour by observing the behaviour of peers and the rewards they receive for behaving in a certain way. In addition, the adolescents' perception of risk is also shaped by their friends' opinions. This influence became even more significant with the emergence of the social media and social networks, which can shape the ideas and opinions regarding the topic of health and lifestyle (Sawyer et al., 2018).

Adolescents move through different contexts in their daily lives and all of them can be a source of influence for their mental health and well-being. Some examples of these contexts are the family, the peer group and the school. On the one hand, the existence of a good relationship between all the actors present in these contexts is an aspect that can improve the adolescents' psychosocial development and emotional well-being (Choi, 2018; Gaspar et al., 2018; Tomé et al., 2012). On the other hand, the poor relationships between students and teachers, poor academic performance, and lack of interest and/or school motivation are some of the factors that are associated with substance use, in the same way as poor relationship with parents and the poor relation with friends, or association with friends who are consumers (Choi, 2018; Gaspar et al., 2018; Marschall-Lévesque et al., 2014; Sawyer et al., 2018; Tomé et al., 2012).

It is also during adolescence that the expectations and aspirations begin to consolidate, namely, in relation to the academic and professional path (Beal \& Crockett, 2013). There is evidence in the literature that points to an association between future expectations and behavioural problems. Thus, adolescents with a more negative view of the future tend to be more susceptible regarding the involvement in risk behaviours, such as alcohol and tobacco consumption (Chen \& Vazsonyi, 2013; McDade et al., 2011; Steiger et al., 2017).

Future expectations are an important component regarding the development of the adolescents' identity and can exert influence in terms of the behavioural change based on the assessment made when future results are considered (Johnson et al., 2014). These expectations can be influenced by disadvantaged situations (e.g., social, economic) experienced by the young people, which has repercussions in terms of how they face the future, health and risks and how they make decisions. There is evidence that points to the association between negative future expectations and involvement in risk behaviors. In addition, it appears that the relationship between substance use and a decrease in positive expectations is reciprocal, with a negative reinforcement cycle between these two variables (i.e., substance use during adolescence contributes to less positive future expectation which, in turn, reinforces the substance use) (Prince et al., 2016).

This study aims to analyze the influence that social factors (relationship with teachers, relationship with peers and family support), future expectations and physical and psychological symptoms have on tobacco and alcohol use among Portuguese adolescents. In addition, it also intends to explore the differences between adolescents with and without consumption of these substances with regard to these variables.

\section{METHOD}

This work is linked to the study Health Behavior in School aged Children/HBSC (Inchley et al., 2016; Matos et al., 2018). The HBSC is a study developed in collaboration with the World Health Organization (WHO) and consists of a survey carried out every 4 years in 44 countries, following an international protocol (Inchley et al., 2020; Roberts et al., 2009). The HBSC aims to study the adolescents' behaviour in their life contexts and their influence on their health/well-being. 
The protocol includes questions about demographic aspects, family, school, friends, health, well-being, sexuality, food, leisure, sleep, physical inactivity, physical activity, substance and medication use, violence, use of technologies, migration and social participation. HBSC has been held since 1982, with Portugal included since 1998 (www.aventurasocial.com). In Portugal, the HBSC 2018 study was approved by the Ethics Committee and MIME (Monitoring of School Surveys). The study includes students from the 6th, 8th, 10th and 12th years, from the various school groups that agreed to participate. Informed consent was obtained from parents or legal guardians, and responses to the survey (online) were voluntary and anonymous.

\section{Participants}

A total of 8215 students participated in this study, 4327 of whom were female (52.7\%), aged between 10 and 22 years old and with an average age of 14.36 years $(S D=2.28)$. The participants were randomly selected from the list of schools in the five regions of Portugal (North, Center, Lisbon and Tagus Valley, Alentejo and Algarve).

\section{Measures and variables}

Considering the objective of this study, the variables present in Table 1 were considered.

\section{Data analysis}

Data analysis was performed using SPSS (Statistical Package for the Social Sciences), version 24 for Windows. To explore the relationships between the variables in this study, the existing correlations were analyzed using Pearson's correlation coefficient. The correlations were analyzed considering the reference values of Cohen (1988). Then, through the analysis of variance (ANOVA), it was intended to verify whether there were differences between the adolescents with and without tobacco and alcohol use, with regard to physical and psychological symptoms, relationship with teachers and peers, family support and future expectations. Finally, the binary logistic regression model was used to explore which variables were related to the adolescents' tobacco and alcohol use.

\section{RESULTS}

Regarding the correlations between the various variables under study (Table 2), a significant relationship between all variables can be observed. The strongest correlations occur between drunkenness and tobacco $(r=0.54)$ and alcohol consumption $(r=0.48)$. Tobacco also has a positive relationship with alcohol $(r=0.47)$. There is a negative relationship between substance use (i.e., tobacco and alcohol) and physical symptoms, psychological symptoms (higher value, less symptoms), relationship with teachers, relationship with peers, family support and future expectations. Thus, the consumption of these substances is reflected in more physical and psychological symptoms, worse relationship with teachers, worse relationship with peers, less family support, and lower future expectations. 
TABLE 1 Measures and variables under study

\begin{tabular}{|c|c|}
\hline Variables & Measure \\
\hline Gender & 1-Male; 2-Female. \\
\hline Tobacco use & 1-No; 2-Yes (Recoded variable: 1 -Never; 2 -From 1 to 30 or more days). \\
\hline Alcohol use & 1-No; 2 -Yes (Recoded variable: 1 -Never; 2 -From 1 to 30 or more days). \\
\hline Drunkeness & $\begin{array}{l}\text { 1-No; } 2 \text {-Yes (Recoded variable: } 1 \text {-No, never; } 2 \text {-Yes, from } 1 \text { to more } \\
\text { than } 10 \text { times). }\end{array}$ \\
\hline Psychological symptoms & $\begin{array}{l}\text { Scale with four items (nervousness, irritability or bad mood, sadness/feeling } \\
\text { "low" and fear), on a five-point Likert scale (1-almost every day and } \\
\text { 5-rarely or never). Minimum score of } 4 \text { and maximum of } 20 . \text { Higher } \\
\text { values reveal fewer psychological symptoms. }\end{array}$ \\
\hline Physical symptoms & $\begin{array}{l}\text { Scale with five items (back pain; neck pain, headache, dizziness and } \\
\text { stomach pain), on a five-point Likert scale (1-almost every day and } \\
5 \text {-rarely or never). Minimum score of } 5 \text { and maximum of } 25 \text {. Higher } \\
\text { values reveal fewer physical symptoms. }\end{array}$ \\
\hline Future expectations & $\begin{array}{l}\text { Scale adapted from Cantril (1965) consisting of } 11 \text { steps (Min. 0-Max. 10). } \\
\text { Higher values show a good future expectation. }\end{array}$ \\
\hline Relationship with teachers & $\begin{array}{l}\text { Scale with } 3 \text { items, on a Likert scale of } 5 \text { points ( } 1 \text {-strongly agree and } \\
5 \text {-strongly disagree). A minimum score of } 3 \text { and a maximum of } 15 \text {. } \\
\text { Higher values reveal a better relationship with teachers. }\end{array}$ \\
\hline Relationship with peers & $\begin{array}{l}\text { Scale with } 3 \text { items, on a 5-point Likert scale, (1-strongly agree and } \\
\text { 5-strongly disagree). A minimum score of } 3 \text { and a maximum of } 15 \text {. } \\
\text { Higher values reveal a better relationship with peers. }\end{array}$ \\
\hline Family support & $\begin{array}{l}\text { Scale with } 4 \text { items, on a 7-point Likert scale ( } 1 \text {-Strongly disagree and } \\
\text { 7-Strongly agree). Minimum score of } 4 \text { and maximum of } 28 \text {. The } \\
\text { higher the value, the greater the family support. }\end{array}$ \\
\hline
\end{tabular}

With regard to drunkenness, the highest correlations are with physical symptoms $(r=0.18)$, psychological symptoms $(r=0.18)$, relationship with teachers $(r=0.17)$ and family support $(r=0.19)$, although all correlations are low. All correlations are negative.

Physical symptoms have a strong and positive relationship with psychological symptoms $(r=0.54)$ and the relationship with teachers have a moderate association with the relationship with peers $(r=0.36)$. Future expectations present a low relationship with regard to psychological symptoms $(r=0.27)$, relationship with teachers $(r=0.25)$ and family support $(r=0.28)$.

Regarding tobacco use, we found significant differences between groups in all the variables, with higher values among the adolescents who do not consume tobacco (Table 3). Thus, the students who do not smoke have better future expectations, greater family support, better relationships with peers and teachers, and less physical and psychological symptoms (higher value, less symptoms). The differences have a small effect size (ES) for future expectations and for the relationship with peers, while the other variables have a medium effect size.

Regarding alcohol use, we find significant differences between groups, in all variables (Table 4). As in the case of tobacco use, all variables also present higher values for students who do not consume alcohol. The differences have an effect size (ES) similar to smoking.

An adjusted logistic regression model was performed (Hosmer and Lemeshow $\chi^{2}=37704$ (8) $p<.001$ ) (Table 5), and the regression equation explained $19.5 \%$ of the variance (Negelkerke $\left.R^{2}=0.195\right)$ in tobacco consumption of all the variables included to explain the tobacco use: only 


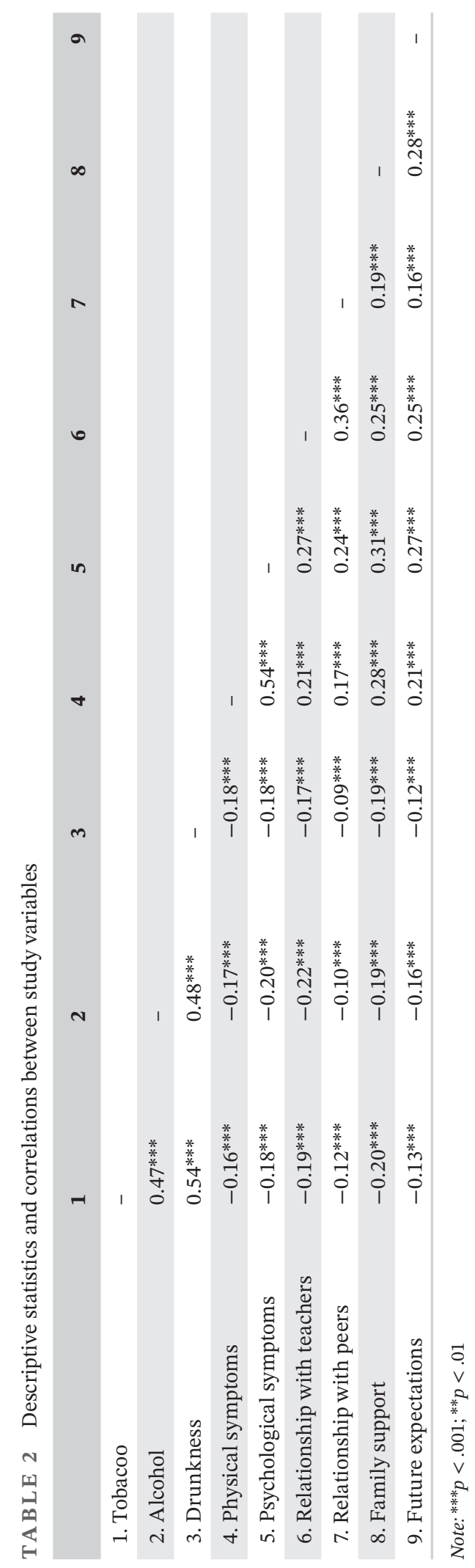


the future expectations and the relationship with peers did not show significant results. The model was controlled for age and gender.

Physical symptoms $(\mathrm{OR}=0.87,95 \% \mathrm{CI}: 0.79-0.97, p=.011)$, psychological symptoms (OR $=0.88,95 \%$ CI:0.81-0.96, $p=0.003)$, family support (OR $=0.97,95 \%$ CI:0.96-0.98, $p<0.001)$ and the relationship with teachers $(\mathrm{OR}=0.90,95 \% \mathrm{CI}: 0.88-0.93, p<.001)$ are directly associated with tobacco consumption.

T A B LE 3 ANOVA—Differences in means between young people with and without tobacco use

\begin{tabular}{|c|c|c|c|c|c|c|}
\hline & \multicolumn{2}{|c|}{ Tobacco use (no) } & \multicolumn{2}{|c|}{ Tobacco use (yes) } & \multirow[b]{2}{*}{$\boldsymbol{F}$} & \multirow[b]{2}{*}{$E S$} \\
\hline & $M$ & $D P$ & $M$ & $D P$ & & \\
\hline Future expectations & 7.37 & 1.85 & 6.78 & 2.11 & $81.13^{* * *}$ & 0.14 \\
\hline Family support & 24.45 & 6.01 & 21.11 & 7.62 & $307.98^{* * *}$ & 0.28 \\
\hline Relationship with peers & 11.93 & 2.33 & 11.20 & 2.69 & $105.66^{* * *}$ & 0.16 \\
\hline Relationship with teachers & 11.50 & 2.42 & 10.25 & 2.69 & $291.73^{* * *}$ & 0.27 \\
\hline Physical symptoms & 4.35 & 0.74 & 4.02 & 0.93 & $203.88^{* * *}$ & 0.22 \\
\hline Psychological symptoms & 3.90 & 1.00 & 3.40 & 1.13 & $265.41 * * *$ & 0.26 \\
\hline
\end{tabular}

Note: ${ }^{* * *} p<.001$.

TABLE 4 ANOVA—Differences in means between young people with and without alcohol use

\begin{tabular}{|c|c|c|c|c|c|c|}
\hline & \multicolumn{2}{|c|}{ Alcohol use (no) } & \multicolumn{2}{|c|}{ Alcohol use (yes) } & \multirow[b]{2}{*}{$\boldsymbol{F}$} & \multirow[b]{2}{*}{$E S$} \\
\hline & $M$ & $D P$ & $M$ & $D P$ & & \\
\hline Future expectations & 7.57 & 1.85 & 6.95 & 1.94 & $124.62^{* * *}$ & 0.18 \\
\hline Family support & 24.89 & 5.89 & 22.43 & 6.91 & $278.31^{* * *}$ & 0.26 \\
\hline Relationship with peers & 12.01 & 2.35 & 11.51 & 2.47 & $81.48^{* * *}$ & 0.14 \\
\hline Relationship with teachers & 11.75 & 2.42 & 10.61 & 2.50 & $416.81^{* * *}$ & 0.32 \\
\hline Physical symptoms & 4.41 & 0.72 & 4.13 & 0.84 & $239.78^{* * *}$ & 0.24 \\
\hline Psychological symptoms & 3.99 & 0.98 & 3.56 & 1.08 & $334.60 * * *$ & 0.29 \\
\hline
\end{tabular}

Note: ${ }^{* * *} p<.001$

T A B L E 5 Logistic regression-Variables associated with the tobacco use (dependent variable)

\begin{tabular}{|llc|} 
& OR (95\% CI) & $\boldsymbol{p}$ \\
\hline Physical symptoms & $0.87(0.79-0.97)$ & .011 \\
\hline Psychological symptoms & $0.88(0.81-0.96)$ & .003 \\
\hline Future expectations & $10.00(0.97-10.04)$ & .816 \\
\hline Relationship with peers & $0.97(0.94-10.00)$ & .053 \\
\hline Family support & $0.97(0.96-0.98)$ & $<.001$ \\
\hline Relationship with teachers & $0.90(0.88-0.93)$ & $<.001$ \\
\hline Constant & 0.02 & $<.001$ \\
\hline
\end{tabular}

Note: The results were adjusted for age and gender.

The variables were entered using the "enter" mode. 
The second model of logistic regression performed (Hosmer and Lemeshow $\chi^{2}=43489$ (8) $p=.000$ ) (Table 6) explains $21.2 \%$ of the variance (Negelkerke $R^{2}=0.212$ ) in alcohol consumption. Of all the variables included in this explanatory model of the Portuguese adolescents' alcohol use, the only one that did not show significant results was the relationship with peers. The variables age and gender are variables of adjustment of the model.

Physical symptoms (OR $=0.87,95 \% \mathrm{CI}: 0.79-0.96, p=.005)$, future expectations $(\mathrm{OR}=0.95$, 95\% CI: $0.91-0.98, p=.003)$, psychological symptoms (OR $=0.87,95 \%$ CI: $0.80-0.94, p<.001$ ), family support (OR $=0.98,95 \% \mathrm{CI}: 0.97-0.99, p<.001)$ and the relationship with teachers $(\mathrm{OR}=0.91,95 \% \mathrm{CI}: 0.88-0.93, p<.001)$ are directly associated with the adolescents' alcohol consumption.

\section{DISCUSSION}

Through the results of this study, it was possible to verify the existence of a negative relationship between tobacco and alcohol use and physical symptoms, psychological symptoms (higher value, less symptoms), relationship with teachers, relationship with peers, family support and future expectations. This means that the consumption of these substances is associated with more physical and psychological symptoms, worse relationship with teachers and with peers, less family support and lower future expectations. A positive relationship between tobacco and alcohol was also observed.

The results showed that the adolescents who do not consume alcohol and tobacco have higher averages in all the variables mentioned, which translates into better future expectations, greater family support, better relationship with peers and with teachers, and fewer physical and psychological symptoms.

There are several factors that can influence adolescents' involvement in alcohol and tobacco use, namely, those related to the parents, peer groups, school and consumption of other substances (Patrick \& Schulenberg, 2014). The literature points to the existence of a tendency towards a positive association between alcohol and tobacco consumption, since the involvement in one of the risk behaviors can lead to the exposure and experimentation with the other (DeRuiter et al., 2014; Janáček et al., 2021; McKee et al., 2007; Verplaetse \& McKee, 2017).

Adolescents go through several events throughout their life cycle that can trigger situations of anxiety and stress. Some examples are aspects related to the school context (e.g., academic

T A B L E 6 Logistic regression-Variables associated with the alcohol consumption (dependent variable)

\begin{tabular}{lll} 
& OR $\mathbf{9 5 \%} \mathbf{C I})$ & $\boldsymbol{p}$ \\
\hline Physical symptoms & $0.87(0.79-0.96)$ & .005 \\
Psychological symptoms & $0.87(0.80-0.94)$ & $<.001$ \\
\hline Future expectations & $0.95(0.91-0.98)$ & .003 \\
Relationship with peers & $10.01(0.98-10.04)$ & .501 \\
\hline Family support & $0.98(0.97-0.99)$ & $<.001$ \\
\hline Relationship with teachers & $0.91(0.88-0.93)$ & $<.001$ \\
\hline Constant & 0.05 & $<.001$ \\
\hline
\end{tabular}

Note: Dependent variable: tobacco use.

The results were adjusted for age and gender. 
pressure, change of school, and bullying situations), the peer group, the family or significant life events (e.g., death of a family member, parents' divorce, etc.) (Choi, 2018). Alcohol and tobacco are often seen as a mean of reducing tension or increasing self-confidence, which tends to increase the use of these substances (Connor et al., 2016). In addition, emotional and psychosomatic problems tend to increase as alcohol consumption also increases (Hoel et al., 2004). Thus, it is important for adolescents to develop appropriate coping strategies as a protective factor against substance use (Gallupe, 2014; McConnell et al., 2014).

There are different contexts that influence adolescents' psychosocial well-being, namely, the family, the school context and the peer group. The quality of the relationships between the adolescents and their peers, parents and teachers is a relevant factor for a more positive and adjusted development, being associated to the prevention of substance use (Choi, 2018; Gaspar et al., 2018; Tomé et al., 2012).

Family cohesion and closeness (Guillén et al., 2015), parental monitoring and quality of family relationships can function as protective factors against the adolescents' involvement in risk behaviors (Fosco et al., 2012; Patrick \& Schulenberg, 2014; van Ryzin et al., 2012). Parental/family monitoring and support also appear as protective factors against the tobacco and alcohol use (Bahr \& Hoffman, 2010; Chaplin et al., 2012; Sudhinaraset et al., 2016), even when peers are users of these substances (Bahr \& Hoffman, 2010). Thus, the relationship with parents is a relevant factor for the adolescents' lives, and they can play a protective and mitigating role with regard to the possible negative influence that may arise from peers. There is evidence that the existence of a negative relationships with parents and peers tends to result in feelings of loneliness and unhappiness, which is reflected in a decrease in the adolescents' psychological well-being (Cerqueira et al., 2019; Tomé et al., 2015).

A study by Gutman et al. (2011) demonstrated that negative family interactions are associated with an increase in the alcohol and tobacco consumption and that positive identification with parents is related to a decrease regarding substance use. Through a study by Ryan et al. (2010) that explored the impact of several parental variables on alcohol consumption, it was possible to observe that factors such as parental monitoring, quality of the relationship between parents and children, parental involvement/support and communication are reflected in a delayed alcohol initiation and subsequently a reduced alcohol-related problems. Thus, family support is a protective factor against the involvement in risk behaviours (Bailey et al., 2011; Fosco et al., 2012; Guillén et al., 2015; van Ryzin et al., 2012), which is in line with the results obtained in this study. It is therefore essential to promote positive and supportive relationships within the family environment in order to reduce the adolescents' probability of engaging in this type of behaviors (e.g., substance use) (Gordon et al., 2020; Moore et al., 2018).

In addition to the family context, the relationship with the peer group is also associated with an increase in the well-being and the adjustment of the adolescents, as well as with a decrease in the involvement in risk behaviours such as substance use (Camacho et al., 2013; Gaspar et al., 2018). Thus, positive relationships and support from peers are associated with a lower prevalence in relation to substance use, which means that they can act as a protective factor against the adolescents' involvement in this type of risk behaviour (Dunn et al., 2011).

Regarding the school context, the relationship established between students and teachers can be a protective or a risk factor, with regard to substance use (Marschall-Lévesque et al., 2014). In addition, the relationship between the adolescents and the school can act as a protective factor against the alcohol and tobacco consumption (Camacho et al., 2013; Gaspar et al., 2018).

Another protective factor regarding substance use is related to future aspirations (Dunn et al., 2011). The evidence points to a positive vision of the future as an aspect that reduces the 
susceptibility to the involvement in risk behaviours, such as alcohol and tobacco consumption (Chen \& Vazsonyi, 2013; McDade et al., 2011; Steiger et al., 2017).

Among the explanatory variables of tobacco consumption, the future expectations and the relationship with peers did not show significant results in this study. Regarding alcohol consumption, only the relationship with peers did not show a significant result. Thus, the physical and psychological symptoms, the family support and the relationship with teachers are associated with the tobacco consumption. On the other hand, the variables associated with alcohol consumption are the physical symptoms, future expectations, psychological symptoms, family support and the relationship with teachers. Future expectations are associated with alcohol consumption, but not tobacco, which is an interesting result of this study.

There are several reasons that can trigger alcohol consumption, namely, social aspects (e.g., for fun), enhancement (e.g., sensation seeking, to get high), coping (e.g., forgetting problems) and conformity (e.g., to fit in, be accepted) (Kuntsche et al., 2014; Kuntsche \& Kuntsche, 2009; Patrick et al., 2011; Patterson et al., 2020; Terry-McElrath et al., 2017; Wicki et al., 2017). Alcohol consumption tends to be associated with a search for relief regarding stress symptoms and an increase in the experience of positive feelings (Kuntsche et al., 2014, 2015; Sayette, 2017; Simões et al., 2017).

The results of a study by Terry-McElrath et al. (2017) reinforce the existing evidence regarding the fact that the adolescents' alcohol consumption appears associated with aspects related to coping. Adolescents with high alcohol consumption can use this substance as a maladaptive strategy to deal with difficulties and adversities. Regardless of the reasons why adolescents need to use coping strategies, the consumption of greater amounts of alcohol tends to be associated with problems such as depression, anxiety and low self-esteem (Gallupe, 2014). All these factors can contribute to a more negative vision of the future, which can be a possible explanation for the fact that future expectations appear as an explanatory variable for alcohol consumption but not for tobacco.

Despite the influence that the peer group can have with regard to substance use (Camacho et al., 2013; Dunn et al., 2011; Gaspar et al., 2018; Trucco et al., 2011), in this study the relationship with peers in particular did not prove to be a predictor of alcohol and tobacco consumption. According to the ecological model of human development, the closer the individual's contexts are, the greater the influence they have on him, since it is in these contexts that there is a higher probability of developing more complex interactions and relationships (Bronfenbrenner \& Morris, 2006). However, the degree of influence of the different relationships established in the same context may change over time (Steinberg \& Silverberg, 1986). In this sense, this result may be due to the fact that the scale used refers specifically to the relationship with classmates, not covering the remaining relationships with other peers and friends, who may have a higher weight regarding substance use (as a protective or risk factor). There is evidence that some of the greatest influences with regard to alcohol consumption come from family and friends, who are the two groups with which the adolescents tend to spend more time (Sudhinaraset et al., 2016). However, it is suggested to explore this result in future studies.

The HBSC study protocol has limitations related to the self-report character and cross-sectional design. However, it is a large-scale study, with random, stratified and representative samples of the country under study, based on a rigorous methodology and which allows a comparison of data between the various years and the different countries involved. 


\section{CONCLUSIONS AND KEY MESSAGES FOR CAREGIVERS, PROFESSIONALS AND PUBLIC POLICIES}

The present study contributed to the increase of knowledge regarding the factors that are related to the consumption of alcohol and tobacco by adolescents. It reinforces the importance of the existence of a work directed towards.

1. the construction of more positive future expectations, either by means of developing serendipity competences and by increasing contextual opportunities and privileging public policies youth friendly;

2. the promotion of a positive and adjusted relationship among adolescents, family members, teachers and peers;

3. the promotion of physical and psychological well-being, namely, by means of developing health literacy, socio-emotional competences, and self-regulation strategies as protective factors against substance use.

It is important for teachers, educators, psychologists and those responsible for public policies to have data on factors that impact the psychosocial well-being of the adolescents and increase their involvement in risk behaviors, so that they can outline, implement and evaluate evidencebased strategies, practices and interventions adjusted to the needs of this population.

The identification of factors that can contribute to alcohol and tobacco use and the design of approaches aimed at reducing these behaviours is a fundamental objective for the public policies and for research (Sznitman \& Engel-Yeger, 2017).

It should also be stressed that there is a need to strengthen the adolescents' competencies in a positive way and through the creation of alternatives, instead of focusing only on the reduction of risk behaviours (Matos \& Ramiro, 2018). It is also important to include the participation of the adolescents in the definition of problematic situations and in the search for solutions (Branquinho et al., 2018, 2019; Kelly et al., 2020), and of course, in creating friendly environments and public policies that allow solution implementation and evaluation.

For future studies, it is suggested to explore the variable related to the relationship of peers and to deepen the future expectations as an explanatory variable of alcohol consumption, but not tobacco, checking as well if there is a different association whether peers are or are not consumers. It might be interesting to use mixed methods to better understand in depth meaning and the impact of future expectations on substance use.

This study highlights the importance of social networks and future expectations as variables that promote the adolescents' well-being, functioning as protective factors with regard to substance use. The need to promote the participation and involvement of the family members, the teachers and the peer group as agents that facilitate the adoption of health-promoting behaviors is emphasized. The intervention must be carried out in a preventive, interventional and integrational logic, acting in all contexts and including all actors of the adolescents' lives, in order to enhance the results obtained.

\section{CONFLICTS OF INTEREST}

The authors declared no potential conflicts of interest with respect to the research, authorship and/or publication of this article.

Ana Cerqueira-Foundation for Science and Technology [Fundação para a Ciência e a Tecnologia-FCT] scholarship (SFRH/BD/148403/2019). 
Fábio Botelho Guedes-Foundation for Science and Technology [Fundação para a Ciência e a Tecnologia-FCT] scholarship (SFRH/BD/148299/2019).

\section{DATA AVAILABILITY STATEMENT}

The data that support the findings of this study are available from the corresponding author upon reasonable request.

\section{ORCID}

Ana Cerqueira (D) https://orcid.org/0000-0001-9883-0210

\section{REFERENCES}

Ansari-Moghaddam, A., Rakhshani, F., Shahraki-Sanavi, F., Mohammadi, M., Miri-Bonjar, M., \& Bakhshani, N. M. (2016). Prevalence and patterns of tobacco, alcohol, and drug use among Iranian adolescents: A meta-analysis of 58 studies. Children and Youth Services Review, 60, 68-79. https://doi.org/10.1016/j.child youth.2015.11.018

Bahr, S. J., \& Hoffmann, J. P. (2010). Parenting style, religiosity, peers, and adolescent heavy drinking. Journal of Studies on Alcohol and Drugs, 71(4), 539-543. https://doi.org/10.15288/jsad.2010.71.539

Bailey, J. A., Hill, K. G., Meacham, M. C., Young, S. E., \& Hawkins, J. D. (2011). Strategies for characterizing complex phenotypes and environments: General and specific family environmental predictors of young adult tobacco dependence, alcohol use disorder, and co-occurring problems. Drug and Alcohol Dependence, 118(2-3), 444-451. https://doi.org/10.1016/j.drugalcdep.2011.05.002

Balaguer, I., Duda, J. L., \& Castillo, I. (2017). Motivational antecedents of well-being and health related behaviors in adolescents. Journal of Human Kinetics, 59(1), 121-130. https://doi.org/10.1515/hukin-2017-0152

Bandura, A. (1986). Social foundations of thought and action: A social cognitive theory. Prentice-Hall.

Beal, S. J., \& Crockett, L. J. (2013). Adolescents' occupational and educational goals: A test of reciprocal relations. Journal of Applied Developmental Psychology, 34(5), 219-229. https://doi.org/10.1016/ j.appdev.2013.04.005

Branquinho, C., Cerqueira, A., Ramiro, L., \& Matos, M. G. (2018). Youth "have a voice"-Qualitative exploration of a participatory action-research program. Acta Psychopathologica, 4(4), 22-33. https://doi.org/10.4172/24 69-6676.100177

Branquinho, C., Gomez-Baya, D., \& Matos, M. G. (2019). Dream Teens: Dar "voz" a la juventud. El impacto de un proyecto de participación social de los jóvenes en Portugal [Dream Teens: Giving "voice" to youth. The impact of a youth social participation project in Portugal]. Análisis y modificación de conducta, 45(171), 25-34.

Bronfenbrenner, U., \& Morris, P. A. (2006). The bioecological model of human development. In R. M. Lerner, \& W. Damon (Eds.), Handbook of child psychology: Theoretical models of human development (pp. 793-828). John Wiley \& Sons Inc.

Camacho, I., Matos, M. G., Simões, C., Tomé, G., \& Diniz, J. (2013). Risk behaviors in Portuguese adolescentes: An explanatory model. Pakistan Journal of Clinical Psychology, 12(1), 3-15.

Cerqueira, A., Gaspar, T., Guedes, F. B., Madeira, S., \& de Matos, M. G. (2019). Sofrimento psicológico, consumo de tabaco, álcool e outros fatores psicossociais em adolescentes portugueses [Psychological distress, tobacco and alcohol use and other psychosocial factors in portuguese adolescentes]. Revista de Psicologia da Criança e do Adolescente, 10(1), 219-228.

Chaplin, T. M., Sinha, R., Simmons, J. A., Healy, S. M., Mayes, L. C., Hommer, R. E., \& Crowley, M. J. (2012). Parent-adolescent conflict interactions and adolescent alcohol use. Addictive Behaviors, 37(5), 605-612. https://doi.org/10.1016/j.addbeh.2012.01.004

Chen, P., \& Vazsonyi, A. T. (2013). Future orientation, school contexts, and problem behaviors: A multilevel study. Journal of Youth and Adolescence, 42(1), 67-81. https://doi.org/10.1007/s10964-012-9785-4

Choi, A. (2018). Emotional well-being of children and adolescents: Recent trends and relevant factors. OECD Education Working Papers, 169. OECD Publishing. 
Cohen, J. (1988). Statistical power analysis for the behavioral sciences, 2nd ed. Lawrence Erlbaum Associates, Publishers.

Connor, J. P., Haber, P. S., \& Hall, W. D. (2016). Alcohol use disorders. The Lancet, 386(10022), 1-11. https://doi. org/10.1016/S0140-6736(15)00122-1

Dahl, R. E., Allen, N. B., Wilbrecht, L., \& Suleiman, A. B. (2018). Importance of investing in adolescence from a developmental science perspective. Nature, 554(7693), 441-450. https://doi.org/10.1038/nature25770

Das, J. K., Salam, R. A., Arshad, A., Finkelstein, Y., \& Bhutta, Z. A. (2016). Interventions for adolescent substance abuse: An overview of systematic reviews. Journal of Adolescent Health, 59(4), S61-S75. https://doi. org/10.1016/j.jadohealth.2016.06.021

DeRuiter, W. K., Cairney, J., Leatherdale, S. T., \& Faulkner, G. E. (2014). A longitudinal examination of the interrelationship of multiple health behaviors. American Journal of Preventive Medicine, 47(3), 283-289. https:// doi.org/10.1016/j.amepre.2014.04.019

Duell, N., \& Steinberg, L. (2019). Positive risk taking in adolescence. Child Development Perspectives, 13(1), 48-52. https://doi.org/10.1111/cdep.12310

Dunn, M. S., Kitts, C., Sandy, L., Goodrow, B., \& Scherzer, G. (2011). Effects of youth asstes on adolescent alcohol, tobacco, marijuana use and sexual behavior. Journal of Alcohol and Drug Education, 55(3), 23-40.

ESPAD Group. (2020). ESPAD Report 2019: Results from the European School Survey Project on Alcohol and Other Drugs. EMCDDA Joint Publications, Publications Office of the European Union. https://www.emcdda.europa.eu/system/files/publications/13398/2020.3878_EN_04.pdf

Fosco, G. M., Stormshak, E. A., Dishion, T. J., \& Winter, C. E. (2012). Family relationships and parental monitoring during middle school as predictors of early adolescent problem behavior. Journal of Clinical Child \& Adolescent Psychology, 41(2), 202-213. https://doi.org/10.1080/15374416.2012.651989

Gallupe, O. (2014). Social status versus coping as motivation for alcohol use. Journal of Youth Studies, 17(1), 79-91. https://doi.org/10.1080/13676261.2013.793792

Gaspar, T., Cerqueira, A., Branquinho, C., \& Matos, M. G. (2018). The effect of a social-emotional school-based intervention upon social and personal skills in children and adolescents. Journal of Education and Learning, 7(6), 57-66. https://doi.org/10.5539/jel.v7n6p57

Gordon, M. S., Russell, B. S., \& Finan, L. J. (2020). The influence of parental support and community belonging on socioeconomic status and adolescent substance use over time. Substance Use \& Misuse, 55(1), 23-36. https:// doi.org/10.1080/10826084.2019.1654513

Guillén, N., Roth, E., Alfaro, A., \& Fernández, E. (2015). Youth alcohol drinking behavior: Associated risk and protective factors. Revista Iberoamericana de Psicología y Salud, 6(2), 53-63. https://doi.org/10.1016/j. rips.2015.03.001

Gutman, L. M., Eccles, J. S., Peck, S., \& Malanchuk, O. (2011). The influence of family relations on trajectories of cigarette and alcohol use from early to late adolescence. Journal of Adolescence, 34(1), 119-128. https://doi. org/10.1016/j.adolescence.2010.01.005

Hoel, S., Magne Eriksen, B., Breidablik, H. J., \& Meland, E. (2004). Adolescent alcohol use, psychological health, and social integration. Scandinavian Journal of Public Health, 32(5), 361-367. https://doi.org/10.1080/14034 940410027894

Inchley, J., Currie, D., Budisavljevic, S., Torsheim, T., Jåstad, A., Cosma, A., Kelly, C., \& Már, A. (2020). Spotlight on adolescent health and well-being. Findings from the 2017/2018 Health Behaviour in Schoolaged Children (HBSC) survey in Europe and Canada. International report. WHO Regional Office for Europe.

J. C. Inchley, D. B. Currie, T. Young, O. Samdal, T. Torsheim, L. Augustson, F. Mathison, A. Aleman-Diaz, M. Molcho, M. Weber, \& V. Barnekow (Eds.) (2016). Growing up unequal: gender and socioeconomic differences in young people's health and well-being: Health Behaviour in School-aged Children (HBSC) study: international report from the 2013/2014 survey. World Health Organization (WHO) Regional Office for Europe. https://www.euro.who.int/_data/assets/pdf_file/0003/303438/HSBC-No.7-Growing-up-unequ al-Full-Report.pdf

Janáček, J., Rybáček, V., \& Ulrichová, M. (2021). Factors associated with high school students' alcohol consumption across three European countries. Journal of Drug Issues, 51(1), 159-180. https://doi.org/10.1177/00220 42620963037 
Johnson, S. L., Blum, R. W., \& Cheng, T. L. (2014). Future orientation: A construct with implications for adolescent health and wellbeing. International Journal of Adolescent Medicine and Health, 26(4), 459-468. https://doi. org/10.1515/ijamh2013-0333

Kelly, C., Branquinho, C., Dzielska, A., Matos, M. G., Melkumova, M., Pavlova, D., Pickett, W., \& Gabhainn, S. N. (2020). Youth participation in the health behaviour in school-aged children study. Journal of Adolescent Health, 66, 6-8. https://doi.org/10.1016/j.jadohealth.2020.03.015

Knoll, L. J., Magis-Weinberg, L., Speekenbrink, M., \& Blakemore, S. J. (2015). Social influence on risk perception during adolescence. Psychological Science, 26(5), 583-592. https://doi.org/10.1177/0956797615 569578

Kuntsche, E., Gabhainn, S., Roberts, C., Windlin, B., Vieno, A., Bendtsen, P., Hublet, A., Tynjälä, J., Välimaa, R., Dankulincová, Z., Aasvee, K., Demetrovics, Z., Farkas, J., van der Sluijs, W., Matos, M. G. M., Mazur, J., \& Wicki, M. (2014). Drinking motives and links to alcohol use in 13 European countries and regions. Journal of Studies on Alcohol and Drugs, 75(3), 428-437. https://doi.org/10.15288/jsad.2014.75.428

Kuntsche, E., \& Kuntsche, S. (2009). Development and validation of the Drinking Motive Questionnaire Revised Short Form (DMQ-R SF). Journal of Clinical Child and Adolescent Psychology, 38, 899-908. https://doi. org/10.1080/15374410903258967

Kuntsche, E., Wicki, M., Windlin, B., Nic Gabhainn, S., Roberts, C., Vieno, A., Bendtsen, P., Hublet, A., Tynjälä, J., Välimaa, R., Dankulincová, Z., Aasvee, K., Demetrovics, Z., Farkas, J., van der Sluijs, W., Matos, M. G. M., \& Mazur, J. (2015). Drinking motives mediate drinking culture differences but not gender differences in adolescent alcohol use. Journal of Adolescent Health, 56, 323-329. https://doi.org/10.1016/j. jadohealth.2014.10.267

Lewis, S., \& Russell, A. (2014). Protecting children and young people from tobacco-related harm: A review. Children \& Society, 28(2), 140-151. https://doi.org/10.1111/j.1099-0860.2012.00472.x

MacArthur, G. J., Harrison, S., Caldwell, D. M., Hickman, M., \& Campbell, R. (2016). Peer-led interventions to prevent tobacco, alcohol and/or drug use among young people aged 11-21 years: A systematic review and meta-analysis. Addiction, 111(3), 391-407. https://doi.org/10.1111/add.13224

Marschall-Lévesque, S., Castellanos-Ryan, N., Vitaro, F., \& Séguin, J. R. (2014). Moderators of the association between peer and target adolescent substance use. Addictive Behaviors, 39(1), 48-70. https://doi.org/10.1016/j. addbeh.2013.09.025

Matos, M. G., \& Ramiro, L. (2018). Challenges for prevention and promotion in the 21st century. Journal of Education, Society and Behavioural Science, 26(2), 1-7. https://doi.org/10.9734/JESBS/2018/43287

Matos, M. G., \& Equipa Aventura Social. (2018). A Saúde dos Adolescentes após a Recessão - Dados nacionais do estudo HBSC de 2018 ebook. [Adolescent Health after the Recession - National data from the 2018 HBSC study ebook].

McConnell, M. M., Memetovic, J., \& Richardson, C. G. (2014). Coping style and substance use intention and behaviour patterns in a cohort of BC adolescents. Addictive Behaviors, 39, 1394-1397. https://doi.org/10.1016/j. addbeh.2014.05.018

McDade, T. W., Chyu, L., Duncan, G. J., Hoyt, L. T., Doane, L. D., \& Adam, E. K. (2011). Adolescents' expectations for the future predict health behaviors in early adulthood. Social Science \& Medicine, 73(3), 391-398. https:// doi.org/10.1016/j.socscimed.2011.06.005

McKee, S. A., Falba, T., O’Malley, S. S., Sindelar, J., \& O’Connor, P. G. (2007). Smoking status as a clinical indicator for alcohol misuse in US adults. Archives of Internal Medicine, 167(7), 716-721. https://doi.org/10.1001/archi nte.167.7.716

Moore, G. F., Cox, R., Evans, R. E., Hallingberg, B., Hawkins, J., Littlecott, H. J., Long, S. J., \& Murphy, S. (2018). School, peer and family relationships and adolescent substance use, subjective wellbeing and mental health symptoms in wales: A cross sectional study. Child Indicators Research, 11(6), 1951-1965. https://doi. org/10.1007/s12187-017-9524-1

Patrick, M. E., \& Schulenberg, J. E. (2014). Prevalence and predictors of adolescent alcohol use and binge drinking in the United States. Alcohol Research: Current Reviews, 35(2), 193-200.

Patrick, M. E., Schulenberg, J. E., O'malley, P. M., Johnston, L. D., \& Bachman, J. G. (2011). Adolescents' reported reasons for alcohol and marijuana use as predictors of substance use and problems in adulthood. Journal of Studies on Alcohol and Drugs, 72(1), 106-116. https://doi.org/10.15288/jsad.2011.72.106 
Patterson, A., Vu, M., Haardörfer, R., Windle, M., \& Berg, C. J. (2020). Motives for alcohol and marijuana use as predictors of use and problem use among young adult college students. Journal of Drug Issues, 50(4), 359377. https://doi.org/10.1177/0022042620917101

Prince, D. M., Epstein, M., Nurius, P. S., Gorman-Smith, D., \& Henry, D. B. (2016). Reciprocal effects of positive future expectations, threats to safety, and risk behavior across adolescence. Journal of Clinical Child \& Adolescent Psychology, 48(1), 54-67. https://doi.org/10.1080/15374416.2016.1197835

Roberts, C., Freeman, J., Samdal, O., Schnohr, C., Looze, M., Nic Gabhainn, S., Iannotti, I., \& Rasmussen, M., \& Matos, M.G. in the International HBSC study group. (2009). The Health Behaviour in School-aged Children (HBSC) study: methodological developments and current tensions. International Journal of Public Health, 54(2), 140-150. https://doi.org/10.1007/s00038-009-5405-9

Ryan, S. M., Jorm, A. F., \& Lubman, D. I. (2010). Parenting factors associated with reduced adolescent alcohol use: A systematic review of longitudinal studies. Australian \& New Zealand Journal of Psychiatry, 44(9), 774-783. https://doi.org/10.1080/00048674.2010.501759

Sawyer, S. M., Azzopardi, P. S., Wickremarathne, D., \& Patton, G. C. (2018). The age of adolescence. The Lancet Child \& Adolescent Health, 2(3), 223-228. https://doi.org/10.1016/S2352-4642(18)30022-1

Sayette, M. A. (2017). The effects of alcohol on emotion in social drinkers. Behaviour Research and Therapy, 88, 76-89. https://doi.org/10.1016/j.brat.2016.06.005

Simões, C., Branquinho, C., Santos, A., \& Matos, M. G. (2017). Motives to use alcohol among adolescents according to their neighborhood characteristics, gender, age, and drinking patterns. Journal of Substance Use, 23, 43-48. https://doi.org/10.1080/14659891.2017.1348550

Steiger, R. M., Stoddard, S. A., \& Pierce, J. (2017). Adolescents' future orientation and nonmedical use of prescription drugs. Addictive Behaviors, 65, 269-274. https://doi.org/10.1016/j.addbeh.2016.08.017

Steinberg, L., \& Silverberg, S. B. (1986). The vicissitudes of autonomy in early adolescence. Child Development, 57, 841-851. https://doi.org/10.2307/1130361

Sudhinaraset, M., Wigglesworth, C., \& Takeuchi, D. T. (2016). Social and cultural contexts of alcohol use: Influences in a social-ecological framework. Alcohol Research: Current Reviews, 38(1), 35-45.

Sznitman, S., \& Engel-Yeger, B. (2017). Sensation seeking and adolescent alcohol use: Exploring the mediating role of unstructured socializing with peers. Alcohol and Alcoholism, 52(3), 396-401. https://doi.org/10.1093/ alcalc/agx008

Terry-McElrath, Y. M., Stern, S. A., \& Patrick, M. E. (2017). Do alcohol use reasons and contexts differentiate adolescent high-intensity drinking? Data from US high school seniors, 2005-2016. Psychology of Addictive Behaviors, 31(7), 775. https://doi.org/10.1037/adb0000314

Tomé, G., Camacho, I., Matos, M. G., \& Simões, C. (2015). Influência da família e amigos no bem-estar e comportamento de risco - modelo explicativo [Influence of family and friends on well-being and risky behavior - explanatory model]. Psicologia, Saúde e Doenças, 16(1), 23-34. https://doi.org/10.15309/15psd160104

Tomé, G., de Matos, M. G., Simões, C., Camacho, I., \& AlvesDiniz, J. (2012). How can peer group influence the behavior of adolescents: Explanatory model. Global Journal of Health Science, 4(2), 26-35. https://doi. org/10.5539/gjhs.v4n2p2

Trucco, E. M., Colder, C. R., \& Wieczorek, W. F. (2011). Vulnerability to peer influence: A moderated mediation study of early adolescent alcohol use initiation. Addictive Behaviors, 36(7), 729-736. https://doi.org/10.1016/j. addbeh.2011.02.008

van Hoorn, J., van Dijk, E., Meuwese, R., Rieffe, C., \& Crone, E. A. (2016). Peer influence on prosocial behavior in adolescence. Journal of Research on Adolescence, 26(1), 90-100. https://doi.org/10.1111/jora.12173

van Ryzin, M. J., Fosco, G. M., \& Dishion, T. J. (2012). Family and peer predictors of substance use from early adolescence to early adulthood: An 11-year prospective analysis. Addictive Behaviors, 37(12), 1314-1324. https:// doi.org/10.1016/j.addbeh.2012.06.020

Verplaetse, T. L., \& McKee, S. A. (2017). An overview of alcohol and tobacco/nicotine interactions in the human laboratory. The American Journal of Drug and Alcohol Abuse, 43(2), 186-196. https://doi.org/10.1080/00952 990.2016.1189927

Wang, C., Hipp, J. R., Butts, C. T., Jose, R., \& Lakon, C. M. (2017). Peer influence, peer selection and adolescent alcohol use: A simulation study using a dynamic network model of friendship ties and alcohol use. Prevention Science, 18(4), 382-393. https://doi.org/10.1007/s11121-017-0773-5 
Wicki, M., Kuntsche, E., Eichenberger, Y., Aasvee, K., Bendtsens, P., Veselská, Z. D., Demetrovic, Z., Dzielka, A., Farkas, J., Matos, M. G., Robert, C., Tynjälä, J., Välima, R., \& Vieno, A. (2017). Different drinking motives, different adverse consequences? Evidence among adolescents from 10 European countries. Drug and Alcohol Review, 36, 731-741. https://doi.org/10.1111/dar.12572

How to cite this article: Cerqueira, A., Gaspar, T., Guedes, F. B., Godeau, E., \& Gaspar de Matos, M. (2022). Alcohol and tobacco use in Portuguese adolescents: The relationship with social factors, future expectations, physical and psychological symptoms. Children \& Society, 00, e12552. https://doi.org/10.1111/chso.12552 